\title{
BALANCE CAPACITY WITH VARIABILITY CAUSED BY HUMAN FACTOR: AN APPLICATION IN A LINE WITH MONTE CARLO SIMULATION
}

\author{
Augusto Sandes Mendes \\ Federal Institute of São Paulo - Suzano Campus, Brazil \\ E-mail: augusto_sandes1986@hotmail.com \\ Adriano Maniçoba da Silva \\ Federal Institute of São Paulo - Suzano Campus, Brazil \\ E-mail: adrianoms@ifsp.edu.br \\ Luiz Teruo Kawamoto Júnior \\ Federal Institute of São Paulo - Suzano Campus, Brazil \\ E-mail: luizteruo@hotmail.com \\ Submission: 31/03/2016 \\ Accept: 31/03/2016
}

\section{ABSTRACT}

The variation in processing times due to the human factor between the working stations of a production line can generate queues resulting in a higher cost to the productive process. The objective of this study was to apply Monte Carlo simulation to balance the capacity of a production line with stations suffering variability in processing time due to the human factor. Simulations of the current situation of the production line were performed by comparing it with a proposal to align capacity with the production restriction in order to reduce inventories process while maintaining full capacity of the line. To develop the study, the selection involves the case of a company's production line in the metal industry that produces machinery and products for metalworking area. The results allowed pointing suggestions for the company to reduce in-process inventory, keeping then total capacity of the line.

Keywords: Line balancing; Production line; Monte Carlo simulation. 


\section{INTRODUCTION}

Aiming to optimize its business operations companies have had an increasingly proactive stance in improvement activities that add value to the final product. Although many internal processes, especially concerning to physical management, are not under direct customer evaluation, its performance directly affects market preferences. In this context, the excess of intermediate stocks and queuing in a production process, which can impact significantly the final cost.

Production Engineering is aimed at the management of production systems in order to maximize all available resources generating satisfactory results, then making the system competitive in today's globalized market.

This scenario puts pressure so that the production management includes in the process of decision making important aspects such as raw material entrance rate in production process, as this rate directly influences production capacity of the company, in the balancing of production lines, in waiting inventory, and materials under processing (WIP - work in process).

Another relevant issue is the variability in production activities time for manual tasks, mainly due to the worker's pace during the work period. This rate directly influences production capacity, becoming indispensable a study to investigate variations in this parameter.

Among the several ways to determine productive capacity, subject to variation, the simulation performed by experiments based on historical data has proven a useful technique for this purpose. Monte Carlo simulation has been recognized as an important tool for decision makers, therefore, allows a problem investigation based on experiments with random number generation (JUNQUEIRA; PAMPLONA, 2002). This method is because the relative frequency of a certain phenomenon occurrence approximates the probability of the same, when the mathematical experiment is repeated several times.

From the importance of capacity studies on a production line and the growing importance of Monte Carlo simulation has received in recent years, it is stated the following question problem: how to balance a productive process which neck has variable processing time? Thus, this study will aim to analyze the ability to balance 
DOI: $10.14807 /$ ijmp.v7i5.455

on a production line that rely on human labor pace proposing changes based on Monte Carlo simulation. The next section deals with the literature review..

\section{LITERATURE REVIEW}

In this section important concepts for the study development were reviewed, treating issues like line balancing, Theory of Constraints, necks, Simulation and Monte Carlo method.

\subsection{Production Lines and the Theory of Constraints}

The Theory of Constraints (TOC) is a scientific method designed by Israeli physicist Eliyahu Goldratt to solve organizational problems susceptible to necks. TOC considers that the production capacity of a "neck constraint" defines the maximum production capacity of a system, that is, a process with the lowest capacity in a production line. Following this approach, this constraint should be located and improved so that the system's production capacity is optimized (GOLDRATT; COX, 2006).

According to Nunes (2004), a system of constraints is made up of resources that limit their ability to achieve better performance in relation to its goal. For the author, the whole system involving flows between different seasons or jobs have at least one restriction.

Goldratt and Cox (2006) suggest a method for improving the necks guided on the following principles:

a) A system works like a chain, and the weakest link determines the overall strength, so it should be found and strengthened.

b) The maximum overall system performance is not equal to the sum of the maximum of all the links.

c) All system works in a relationship of cause and effect. Among the adverse events observed, some are causers and some are effects.

d) Undesirable effects are not considered problems but indicators. They are results and hidden causes that should be located and treated.

e) A solution is perishable. It deteriorates with time. 
DOI: 10.14807/ijmp.v7i5.455

f) Most of the constraints stems from policies rather than physical factors. The political constraints are of more complex identification and addressing.

g) Ideas are not solutions. The best ideas do not have potential until their implementation. Most of the ideas still fail in the deployment process.

Goldratt and Cox (2006) compare a production line with a walk of a Boy Scout troop in single file. Each have their walking pace as well as production processes have their capacity. If the fastest scout is placed in the front, the group tends to disperse. One solution is to group the scouts so that the slower coordinate the walk. Another solution would be to tie the scouts with a rope to make them walk the same pace, on the speed of the slowest, namely the constraint pace. The challenge is to reduce the dispersion of activities without increasing the total time to complete the cycle.

The Theory of Constraints considers that the system neck capacity defines its maximum production, for that reason its disposal should be sought in order to speed up the system.

According to Goldratt and Cox (2006), the necks of a production line can be identified by the previous semi-finished material accumulation to a certain process. For the authors, efficiency, downtime, and use of this resource should be frequently monitored to avoid losses in the rest of the production process.

In an industrial process, studies to eliminate necks can also be accompanied by financial analyses. The existence of neck involves costs caused by waiting or by the intermediary stock in view of this waiting. However, there is the risk of replacing costs caused by necks for some other kind of cost, not observed, while necks are seen as the main cause. The decision for improvement in relation to a neck is closely linked to improving the process cost. It is therefore necessary to define the neck resource cost and its modifications within the activity to choose the best way of treating this problem. The next section deals with the influence of human behavior in modeling.

\subsection{Human behavior influence in modeling}

Many tasks in the productive environment require greater or lower amount of operators' manual work. Human labor can have important effects in the production 
process such as reduced production rates due to fatigue. Factors considered in the composition of fatigue are: physical exertion, mental stress and monotony. Physical exertion is the physiological wear and tear to a muscle activity. The mental effort is the physiological wear due to a mental activity in which the work the operator performs requires focused attention. Monotony is the routine work (EHRHARDT et al., 1994).

According to Baines et al. (2004), computer simulations have traditionally guided in technologies systems (e.g. machines, conveyors), then represented by deterministic or stochastic data. However, such simulations often overestimate the manufacturing systems capacity because they do not consider the human factor. This can cause serious problems when the proposed system is implemented, and then does not meet the above expectations to the model generation.

One of these omissions is the relationship between a person's performance and factors affecting this performance. This is particularly apparent when modeling industrial systems that have high proportion of manual operations (ERNHARDT; SCHILLING, 1997). Consequently, to improve the simulation accuracy is necessary to represent those more realistically with the inclusion of delays resulting from behavioral aspects. The next section deals with the simulation theme.

\subsection{Simulation}

The simulation consists in structuring a model that aims to represent an operation or real-world situation. This model uses several parameters, detailing the system under review with some fidelity. The purpose of this technique is to provide support for decisions when conducting pilot studies or actual testing is not feasible, for either security, financial, technological resources or time reasons (AMANIFARD et al., 2011). However, the quality of the analysis generated by simulated models as well as its results are directly linked to the entrance data quality and model structure (CATELLI, 2010). Thus, to perform data simulation correctly representing the problem is something essential.

The simulation can also be understood as a process that makes possible the development of a useful model for analyzing a real experience. For Moreira (2010), the simulation is based on building a model that approaches the reality, which is operated several times, always analyzing the results from a certain level of 
DOI: 10.14807/ijmp.v7i5.455

manipulation and control. The use of computers facilitates this trial, allowing greater accuracy of results due to the possibility of carrying out numerous interactions on the system at hand.

According to Garcia, Lustosa and Barros (2010), simulation models can be divided into deterministic and probabilistic. The first group involves analysis of accurate settings to obtain specific results. The second uses statistical assumptions, which incorporate probabilistic behavior involved in the system variables behavior.

For Andrade (2009), the simulation makes possible to perform deductions on the system behavior through experiments. For Ehrlich (1985), the simulation method is used to analyze a system performance by devising a model that deals with similar characteristics to the original system. Possible problem responses can provide a reliable model (HARRELL, 2002).

However, the use of simulation is a step preceding the new policies and decision alternatives draft. For the problem formulation data collection is required, which should be enough and meaningful to the decision-making process (ANDRADE, 2009).

Once the model is established, it is necessary to know the efficiency possible to obtain from the simulation results. One should also perform tests that could demonstrate the propositions consistency (ANDRADE, 2009).

Thus, by reviewing historical data, it is possible to create a model to study the capacity variation and possible queues on a production process by simulation methods. The next section deals with Monte Carlo simulation.

\subsection{Monte Carlo simulation method}

The origin of the term Monte Carlo dates back to a parallel with a casino roulette located in the principality of Monaco. Von Neumann, around 1944, was one of the term farmers used to name the mathematical technique for solving nuclear physics problems, which was also used for the creation of the nuclear bomb (LOESCH, HEIN, 2009; GARCIA, LUSTOSA ; BARROS, 2010).

The Monte Carlo method stems from the probabilistic model that performs random events simulations (GARCIA, LUSTOSA; BARROS, 2010). According Loesch and Hein (2009), Monte Carlo technique consists in the operation of a 
hypothetical roulette leading to random results, which is controlled so that the results lead to a certain interpretation.

For Moreira (2010), Monte Carlo method focuses on probabilistic variables behavior simulation by generating random values so that it has a set of possible occurrence of the phenomenon. According to Garcia, Lustosa and Barros (2010), for the implementation of Monte Carlo method, some basic steps are needed, such as: (1) defining variables and collecting historical data; (2) identifying the collected variables distribution; (3) modeling the probability distribution for the defined variables; (4) defining intervals of random numbers; (5) generating random numbers and; (6) simulating experiments.

As for Morais (2010), Monte Carlo method comprises the following steps: (1) identification of probability distributions with respect to the variables addressed; (2) establishment of the cumulative probability distributions for each variable identified; (3) definition of the random numbers ranges for each variable; (4) generation of random numbers; and (5) experiments simulation.

The random numbers, according to Moreira (2010), should be allocated from sets of numbers compatible with the range extension to which they belong in the real context, keeping a relationship between the set of random numbers and the frequencies.

As discussed in previous sections, in a production line the flow should be adjusted by the neck. In this study, as the studied process has variable processing rate, it is viable to state the following research hypothesis:

H1 - In a production line with work station which neck has variable production time, capacity should be adjusted from this process including variation.

Next section presents the methodology of the study.

\section{METHODOLOGY}

To prepare this study the case study method was used, because it is a methodological approach to research, when aiming to understand, explore or describe events and complex contexts in which several factors are involved. Yin 
DOI: $10.14807 /$ ijmp.v7i5.455

(2001) argues that this approach fits when the researcher seeks answers to the "How?" and "Why?"

So, Yin (2001) defines "case study" based on the study characteristics phenomenon and based on a set of characteristics associated with the data collection process and analysis strategies thereof.

As for approach methods, this research is classified as qualitative and quantitative. The need for qualitative interpretation of data obtained through information accessed during the case study. Quantitative because data quantification through mathematical tools provides better comprehension of the factors involved (GIL, 1999).

Regarding the purpose, this research is classified as descriptive, that is the one which sets clear and well outlined features of a given population or phenomenon. For this, it involves standardized and structured techniques of data collection and is primarily motivated by the need to solve problems concretely and more immediate. Therefore, it has practical purpose, as opposed to pure research, motivated primarily by intellectual curiosity of the researcher and located mainly in the speculation level (VERGARA, 2006).

The research was conducted in four stages. The first step was to characterize the company's production line, specifically the line where there is heavy reliance on manual labor and that there is great variability in production rates due to the pace of work, identifying, establishing and defining the items probability distributions. The second stage consisted of data processing and modeling from the production system

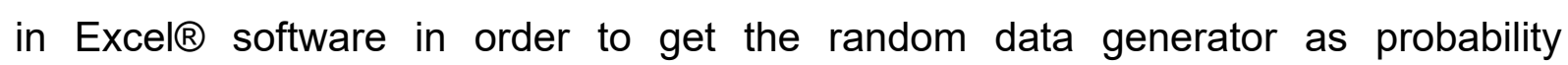
distributions.

The third stage was the data simulation into a set of 160 experiments, followed by 1,000 replications equivalent to monthly charge of producing 160 hours. With data of the line current situation and the proposed leveling with the capacity of the neck. Finally, the fourth stage was the analysis and comparison of the two simulations, cited in the third stage. The next section presents the results analysis. 
DOI: 10.14807/ijmp.v7i5.455

\section{RESULTS ANALYSIS}

\subsection{Characterizing case and production line}

The company chosen for the case study is a Japanese multinational organization, manufacturer of machinery and equipment for the metal-mechanic sector, headquartered in Suzano, Brazil.

The studied process was an intermediate production line in the components machining sector, it has a demand of 10,000 items/month and time available in one round of 160 hours/month. The production line has 3 milling machines with intermediate inventory, earlier at each process, in which there is dependence of the processes precedence, as shown in Figure 1.

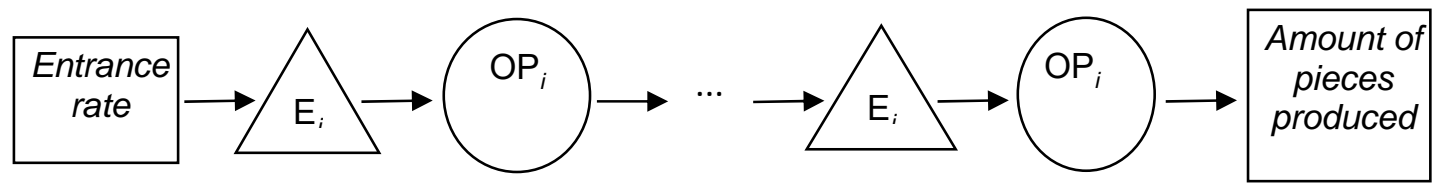

Note:

$\mathrm{E}$ : Intermediate inventory for operation on station $i$;

$\mathrm{OP}=$ Operation on station $i$;

$i$ : Work station $=i=1,2,3$.

Figure 1: Production line processes mapping

Capacity and variability data were collected from company reports and operations chronoanalysis. The variability in the entrance rate of the items on the production line has been converted into probability as shown in Table 1.

Table 1: Relative probability in entrance rate of the production line

\begin{tabular}{|l|l|}
\hline Entrance rate (items/hour) & Relative probability \\
\hline 100 & $20 \%$ \\
\hline 84 & $20 \%$ \\
\hline 68 & $60 \%$ \\
\hline Total: $252 \quad$ Total: $\mathbf{1 0 0} \%$ \\
\hline \multicolumn{2}{|c|}{ Source: Authors of the study }
\end{tabular}

The Station 1 operation has 80 items/hour of production capacity, and may be flexible in increase and decrease of $20 \%$ capacity. Operation at station 2 has constant production capacity of 200 items/hour, due to the fact of using an automated and relatively modern equipment than the other stations. At Station 3, there is also 
DOI: 10.14807/ijmp.v7i5.455

variability in production capacity due to the high degree of manual operations utilization. Table 2 presents probability data related to the Station 3operation capacity.

Table 2: Relative probability in operation productive capacity on Station 3

\begin{tabular}{|l|l|}
\hline Capacity Station $\mathbf{3}$ (items/hour) & Relative probability \\
\hline 60 & $12 \%$ \\
\hline 54 & $88 \%$ \\
\hline Total: $\mathbf{1 1 4}$ & Total: $\mathbf{1 0 0} \%$ \\
\hline \multicolumn{2}{|c|}{ Source: Authors of the study }
\end{tabular}

The monthly demand of the company in the reported period (July 2015) was 10 thousand items. With the time data available of monthly demand, the average capacity required was calculated as shown in Equation 1.

Average capacity $=\frac{\text { Demand }}{\text { available time }}=\frac{10.000 \text { items }}{160 \text { hours }}=62,5$ items $/$ hour

From the presented data, it is identified that the Station 3 does not meet the demand of 10,000 items/month, that is, the position is the production line neck, because it is not shown in any of the cases of relative probability higher or equal to the calculated average capacity, and it limits the total capacity of the line as the number of items processed in Station 3, which is 51.12 items/hour on average. The next section explains the simulation model.

\subsection{Data treatment and system modeling}

With data from the characterization of the production line, it was developed, in Excel $B^{\circledR}$ software, data processing and modeling of the system to be simulated.

For generation of random numbers, the entrance and the Station 3 capacity rates, the array was obtained with the relative probabilities on the production history, Tables 1 and 2 and cumulative probability for the correct assignment of the distribution of numbers to be generated. Table 3 shows the distribution of accumulated probabilities. 
INDEPENDENT JOURNAL OF MANAGEMENT \& PRODUCTION (IJM\&P)

http://www.ijmp.jor.br

v. 7, n. 5, Special Edition IFLOG 2015

ISSN: 2236-269X

DOI: 10.14807/ijmp.v7i5.455

Table 3: Accumulated distribution of the model variables

\begin{tabular}{|c|c|c|c|c|c|}
\hline \multicolumn{3}{|c|}{ (a) Entrance rate } & \multicolumn{3}{|c|}{ (b) Capacity on Station 3} \\
\hline Probability & $\begin{array}{l}\text { Accumul. } \\
\text { Probability }\end{array}$ & $\begin{array}{l}\text { Entrance } \\
\text { rate }\end{array}$ & Probability & $\begin{array}{l}\text { Accumul. } \\
\text { Probability }\end{array}$ & Capacity \\
\hline 0,2 & 0 & 100 & 0,12 & 0 & 60 \\
\hline 0,2 & 0,2 & 84 & 0,88 & 0,12 & 54 \\
\hline 0,6 & 0,4 & 68 & & 1 & 54 \\
\hline & 1 & 68 & & & \\
\hline
\end{tabular}

The production system modeling was developed as shown in Table 4, with the entrance, waiting, missing, cumulative waiting, cumulative absence, and work in process (WIP) rates for each working station.

Table 4: Simulation Modeling (Station 1)

\begin{tabular}{|c|c|c|c|c|c|c|c|c|}
\hline $\begin{array}{l}\text { (1) } \\
\text { Hour }\end{array}$ & $\begin{array}{l}\text { (2) Entrance } \\
\text { rate }\end{array}$ & $\begin{array}{c}\text { (3) } \\
\text { Absen } \\
\text { ce }\end{array}$ & $\begin{array}{c}\text { (4) } \\
\text { Waiting } \\
\text { OP1 }\end{array}$ & $\begin{array}{c}(5) \\
\text { Cumulative } \\
\text { Absences }\end{array}$ & $\begin{array}{c}\text { (6) } \\
\text { Cumulative } \\
\text { Waiting }\end{array}$ & $\begin{array}{l}(7) \\
\text { Line } \\
\text { OP1 }\end{array}$ & $\begin{array}{l}\text { (8) } \\
\text { Cap. } \\
\text { OP1 }\end{array}$ & $\begin{array}{l}\text { (9)WIP } \\
\text { OP1 }\end{array}$ \\
\hline 1 & $\begin{array}{c}\sim \text { Dist (Table } \\
\text { 3-a) }\end{array}$ & $\begin{array}{c}\text { Max } \\
(8-2 ; 0)\end{array}$ & $\begin{array}{c}\text { Max } \\
(2-8 ; 0)\end{array}$ & $\sum_{3}$ & $\sum_{4}$ & $\begin{array}{c}\operatorname{Max} \\
(6-5 ; 0)\end{array}$ & 80 & $\begin{array}{l}\text { Min } \\
(2 ; 8)\end{array}$ \\
\hline
\end{tabular}

Source: Authors of the study

For calculating the input rate and OP3 Queue random numbers were used to generate simulation from the cumulative distributions in Table 3 . The molded items were simulated for 160 hours, which is the time available in one turn for one month of production. The absence was obtained from the subtraction between the maximum station capacity and the input rate and zero. Conversely, the wait was obtained by the maximum by subtracting the entry fee for the ability and zero.

The following variables were analyzed: (1) Total of items that the entrance rate resulted; (2) Maximum number of items in the queue at Station 1 (Queue OP1); (3) Maximum number of items in the queue at the Station 3 (Queue OP3); and (4) Total items processed at Station 3. The next section presents the simulation results.

\subsection{Simulation results of the production line current situation}

Result simulation for total items that the entrance rate resulted is shown in Table 5.

Table 5: Total items resulted by entrance rate

\begin{tabular}{|l|l|}
\hline Total items & 12.784 \\
\hline Average (items/hour) & 79,90 \\
\hline $\begin{array}{l}\text { Standard deviation } \\
\text { (items/hour) }\end{array}$ & 13,93 \\
\hline
\end{tabular}


DOI: $10.14807 /$ ijmp.v7i5.455

The result showed that the total items that the input rate, working at current rates, even with variability demand, is greater than 10,000 items. The maximum number of items in the Station 1 queue has resulted in 30 pieces, which presents a very small result in the total of items that entered the line, with an average of 1 unit on the OP1 row.

The maximum number of items in Station 3 queue, showed a maximum queue of 3,367 items that accumulate along the simulation, presenting an approximately linear behavior, as shown in Figure 2.

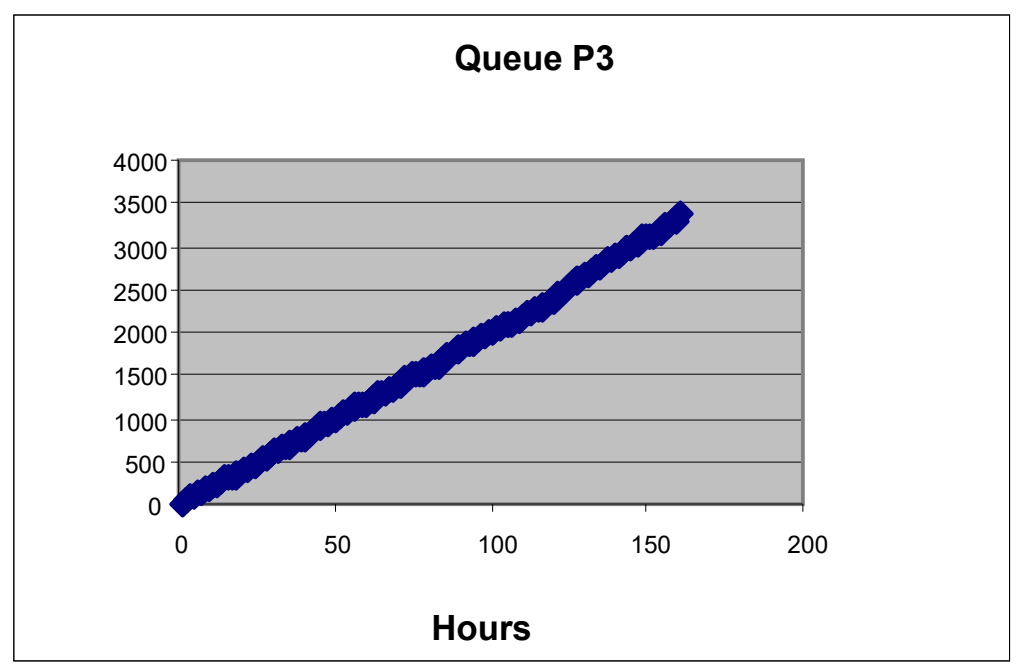

Figure 2: Line behavior on Station OP3

This occurred because queue 3 capacity is reduced, according to Table 6 , from the simulation results.

Table 6: Total items Station 3 produced on current situation simulation

\begin{tabular}{|l|l|}
\hline Total items & 8.742 \\
\hline Average (items/hour) & 54,64 \\
\hline $\begin{array}{l}\text { Standar deviation } \\
\text { (items/hour) }\end{array}$ & 1,85 \\
\hline
\end{tabular}

Due to limitations on investments related to the capacity increase of the OP3 station, the company works with overtime schedule to make up the difference between demand and capacity constraint of the OP3 station. From these results, where the neck of the production process has been identified, the next section presents the result of the equilibration process for the production line. 
DOI: 10.14807/ijmp.v7i5.455

\subsection{Simulation with proposed values for neck capacity balance}

Values with the input rate change to those shown in Table 3 were simulated. The decrease of 16 batches of items of the input rhythm were performed in each probability, as it is the standard batch the one processed in previous queues. Thus, the new cumulative distribution table can be seen in Table 7 .

Table 7: Modified entrance rate

\begin{tabular}{|l|l|l|}
\hline Probab. & $\begin{array}{l}\text { Accumul. } \\
\text { Probability }\end{array}$ & Entrance rate \\
\hline 0,2 & 0 & 84 \\
\hline 0,2 & 0,2 & 68 \\
\hline 0,6 & 0,4 & 52 \\
\hline 1 & 1 & 52 \\
\hline
\end{tabular}

With these changes in entrance rate, total items on simulation of 160 hours are presented in Table 8.

Table 8: Total items entrance rate resulted with modifying simulation

\begin{tabular}{|l|l|}
\hline Total items & 10.096 \\
\hline Average (items/hour) & 63,10 \\
\hline Standar deviation (items/hour) & 13,31 \\
\hline
\end{tabular}

The result shows that even with the rhythm decrease in the entrance rate, it still shows the total items near the demand of 10,000 items.

The same simulation was performed to decrease the capacity of the Station 1 from 80 items/hour to 60 items/hour in order to align the average input rate of items, because it is flexible due to the quantities to be processed, so there is no lack of items on the OP3 station and it loses capacity if there is a shortage, and in an attempt to decrease in the station queue 3 .

The maximum number of items in the OP1 queue was 88 items representing a very small value in relation to entrance rate, with an average of 14 items in the line of OP1 station.

The maximum number of items in the OP3 station queue, showed a maximum queue of 567 items that accumulate over the simulation, showing an increasing trend, as shown in Figure 3. 


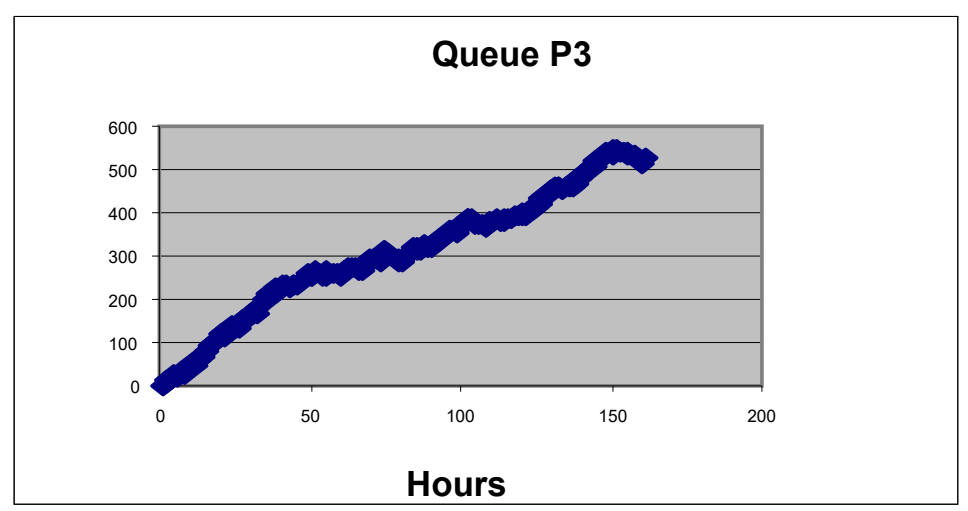

Figure 3: Line behavior on station OP3 with changes on entrance rate and capacity on Station 1.

Total items processed in station OP3 is shown in Table 9 together with the simulation results with changes proposal.

Table 9: Total items Station 3 produced in the changes proposal simulation

\begin{tabular}{|l|l|}
\hline Total items & 8.742 \\
\hline Average (items/hour) & 54,64 \\
\hline $\begin{array}{l}\text { Standar deviation } \\
\text { (items/hour) }\end{array}$ & 1,85 \\
\hline
\end{tabular}

The results presented in total items processed in Station 3 is identical to those shown in simulation with the condition, that is, there was no lack of pieces in Station 3 , even with decrease of entrance rate and of Station 1 capacity rhythm.

Aiming to verify variation sensibility of OP3 capacity and the Queue effect, the study conducted replications of the simulation carried out from Station 1 processing variance capacity. According to the exposed in Figure 4, there is convergence of the values simulated in the replications. 
DOI: $10.14807 /$ ijmp.v7i5.455

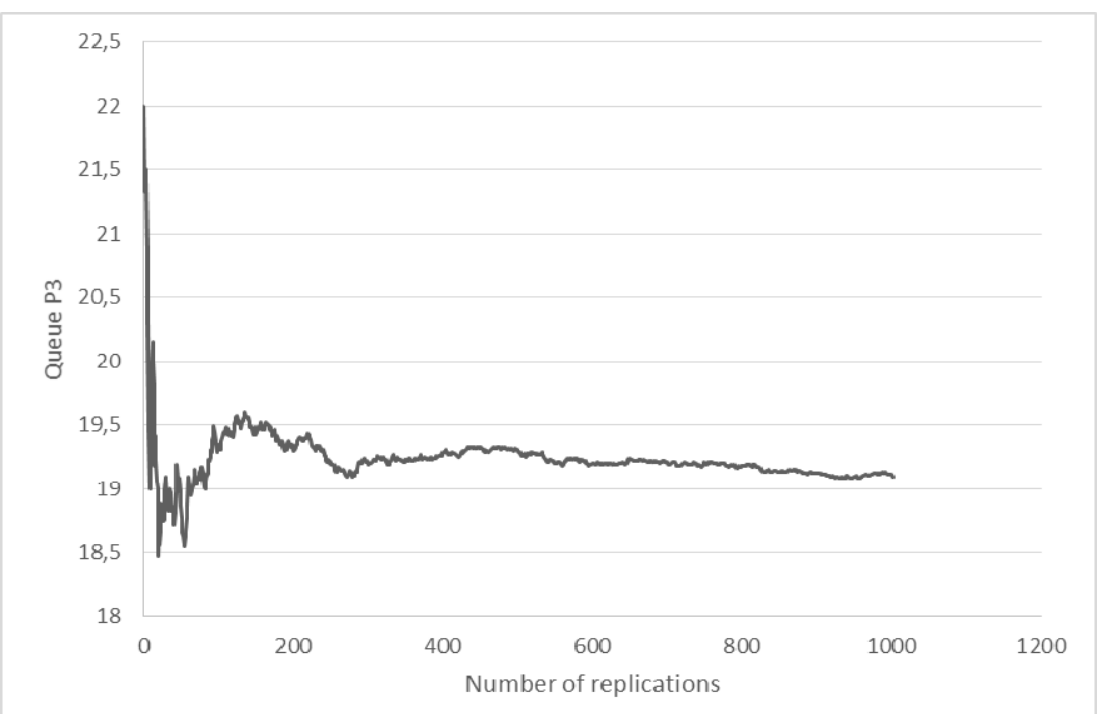

Figure 4: Average Queue replications in Station 3

Once values established, it was possible to analyze average queue behavior in function of the variance on processing time of Station 1. Assuming what literature preconizes about, if stations have similar processing time, there will not have queue, it could be verified queue sensibility, in the sense that a maximum capacity of standardization was analyzed in Station 1, noting that Station 3 has variance.

In order to investigate this result, a binary codification was used every time Station 3 did not show queue, this is when condition would be zero, and one in the opposite situation. The result of this counting is shown in Figure 5.

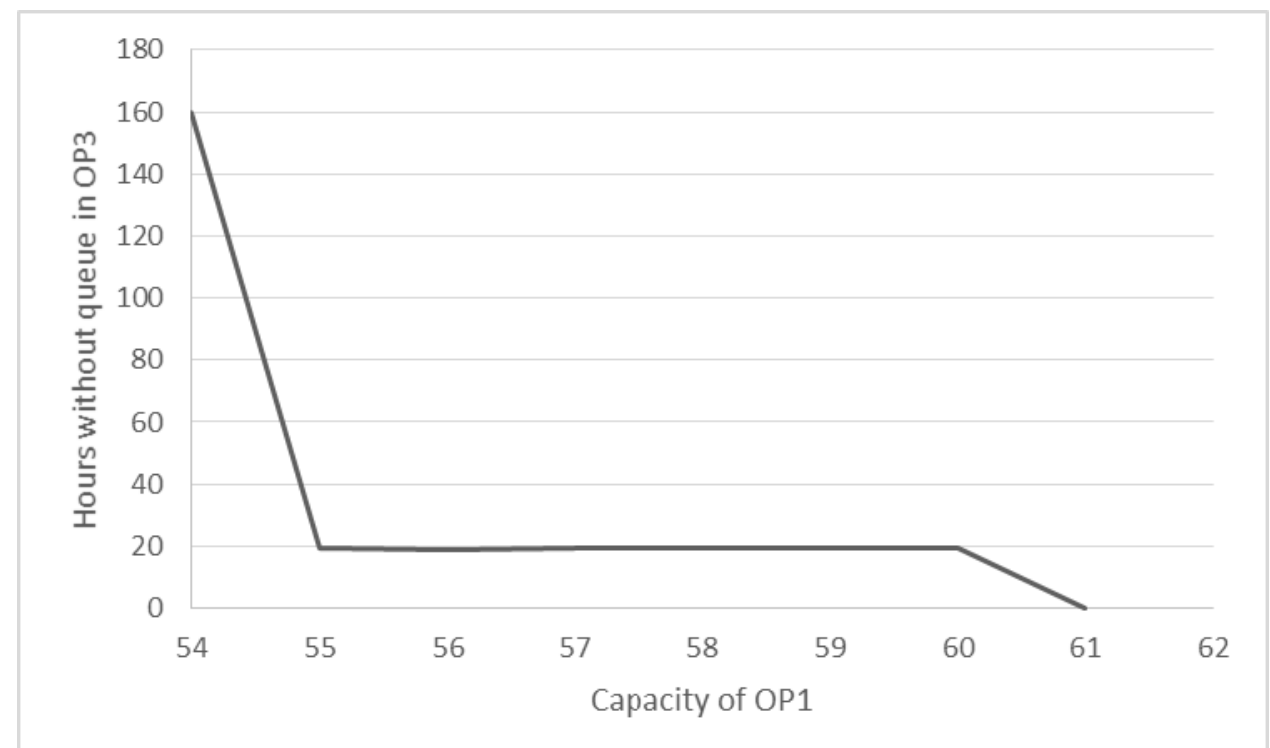

Figure 5: Relation between OP1 and OP3 queue 
From the understanding of Figure 5, it is possible to state that when Station 1 capacity is equal to Station 3 (average of 54 ), there is no queue in simulated hours, that is, the codification carried out is 0 in all observations. When Station 1 capacity varied between 55 and 60 units, the amount of hours representing queue is stable in 20. At last, from 61 units all the simulated hours start generating queues.

The result is shown in Figure 5, allowing to discuss some important aspects, what is done in the next section.

\section{RESULTS DISCUSSION}

The study results allow affirming that, in a production line with working stations using different processing times, preceding processes should be balanced in the station where the neck is located. This way, the study result is according to what Goldratt and Cox (2006) stated, in regards to the system identification and parameterization in relation to the neck.

As stated Nunes (2004), the studied production system did not show constratints limiting total capacity because constraint was in Station 3. Moreover, it was possible to model productive process variability coming from human behavior that would represent eventual manual Works performed in the operations environment (BERNHARDT; SCHILLING, 1997).

Monte Carlo simulation was a useful tool to investigate particularities of the problem analyzed in regards to the variability of entrance and processing rates and its effect on the processing queue corresponding to productive neck. As announced by Andrade (2009) and Harrel (2002), the system trustily allowed to replicate, considering the limitations from simplification, so that production system could be modelled for analysis.

It is believed that the main result arises from the analysis of a production line which neck has variation in its processing rate. Especially the foregoing in Figure 5, it should be parameterize the foregoing processes to the neck so that their processing rates do not exceed the maximum variation of the neck processing rate.

There is a usefulness of the result obtained by the fact that, as the examined example, if the Station 1 was parameterized with 55 processing rate, this result would 
DOI: $10.14807 /$ ijmp.v7i5.455

not be efficient because a parameterization with 60 would result in the same amount of idle time in production process. The next section presents the findings.

\section{CONCLUSIONS}

The results of this study allow us to reaffirm the usefulness of Monte Carlo simulation method, to generate random rates and capacities in the range of accumulated probability as getting inputs as field data obtained through reporting production and chrono-analysis.

The proposal of aligning capacity to the productive neck, which is located in the premise of the theory of constraints, it proved to be, in fact, the maximum capacity that can be achieved with the system. Thus, all or any effort capacity variation should focus on previous or subsequent cases.

Based on the results shown in the simulations, by making comparisons between current line status and the proposal of aligning capacity to the neck, there were significant results in the possibility of producing excessive reduction in entrance rate from 12,784 items to 10,096 items (21\% reduction) and in Station 3 queue, which resulted in the current condition simulation in 3,367 items at the end of 160 hours of simulation, for the result of the proposed condition of 567 items (83\% reduction of items waiting to be processed).

This study allows the model to be replicated in similar cases of productive necks, which have as essential difficulty the entrance rates variability, capabilities for predictions and capacity simulations, allowing even comparisons with similar models and simulations with events discrete.

It is concluded that in simulation models, the human resource should not be statistically treated in the same way that automated features. The results indicate significant variations (in 5 processing units), and therefore should be considered in the analysis model.

The limitations verified are associated to the fact that the process has been simulated using Monte Carlo simulation in discrete time, since the latter form considers the dynamic view of the item in question. Also another limiting factor may have been the amount of stations in the production process analyzed, 3 stations, a fact that may compromise the results of the conclusions and generalizations. 
INDEPENDENT JOURNAL OF MANAGEMENT \& PRODUCTION (IJM\&P)

http://www.ijmp.jor.br

v. 7, n. 5, Special Edition IFLOG 2015

ISSN: 2236-269X

DOI: 10.14807/ijmp.v7i5.455

Future studies may lean on the balance of the production line capacity with a bigger amount of stations, as well as in the presence of greater number of variability sources, because in this study, only one was identified 1, the OP3 station. Furthermore, it is necessary to perform the analysis using discrete simulation.

\section{REFERENCES}

AMANIFARD, N.; RAHBAR, B.; HESAN, M. (2011) Numerical simulation of the mitral valve openning using smoothed particles hydrodynamics. Proceedings of the World Congress in Engineering, v. 3, july.

ANDRADE, E. L. (2009) Introdução à pesquisa operacional: métodos e técnicas para análise de decisão. Rio de Janeiro: LTC.

BAINES, T.; MASON, S.; PEER-OLAF, S.; LADBROOK, J. (2004) Humans: the missing link in manufacturing simulation? Simulation Modelling Practice and Theory, v.12, p.515-526.

CATELLI, A. (2010) Controladoria: uma abordagem da gestão econômica GECON. São Paulo. Atlas.

EHRHARDT, L.; HERPER, H.; GEBHARDT, H. (1994) Modelling strain of manual work in manufacturing systems, in: Proceedings of the 1994 Winter Simulation Conference, Orlando, Florida, pp. 1044-1049.

ERLICH, P. J. (1985) Pesquisa Operacional: curso introdutório. $5^{\text {a }}$ Ed. São Paulo: Atlas.

ERNHARDT, W.; SCHILLING, A. (1997) Simulation of group work processes in manufacturing, in: Proceedings of the 1997 Winter Simulation Conference, Atlanta, Georgia, pp. 888-891.

GARCIA, S.; LUSTOSA, P. R. B.; BARROS, N. R. (2010) Aplicabilidade do Método da Simulação de Monte Carlo na Previsão dos Custos de Produção de Companhias Industriais: O caso Companhia Vale do Rio Doce. Revista de Contabilidade e Organizações - FEA-RP/USP, v. 4, n. 10, p. 152-173, set-dez.

GIL, A.C. (2010) Como elaborar projetos de pesquisa. 5. ed. São Paulo: Atlas.

GOLDRATT, E. M.; COX, J. (2006) A meta: um processo de melhoria contínua. São Paulo: NBL Editora.

HARREL, C. R. et al. (2002) Simulação: otimizando sistemas. 5ª Ed. São Paulo: IMAM.

JUNQUEIRA, K.C., PAMPLONA, E. O. (2002) Utilização da Simulação de Monte Carlo em estudo de viabilidade econômica para a instalação de um conjunto de rebeneficiamento de café na Cocarive. XXII Encontro Nacional de Engenharia de Produção, outubro de 2002, Curitiba - PR.

LOESCH, C; HEIN, N. (2009) Pesquisa Operacional: fundamentos e métodos. São Paulo: Saraiva.

MORAIS. M. F. (2009) Pesquisa Operacional Aplicada - Apostila. Curso de Engenharia de Produção Agroindustrial. Fecilcam: Campo Mourão. 
MOREIRA, D. (2010) Administração da Produção e Operações. 2 ed. São Paulo: Cengage Learning.

NUNES, G. A. (2004) Desenvolvimento de um método de melhoria do processo logístico de uma empresa prestadora de serviços de distribuição de energia elétrica pela identificação de gargalos e avaliação dos custos das atividades desenvolvidas. (Dissertação de mestrado). UFRGS. Porto Alegre, RS.

VERGARA, S. C. (2006) Projetos e relatórios de pesquisa em administração. 7 ed. São Paulo: Atlas.

YIN, R. K. (2001) Estudo de caso: planejamento e métodos. 2. ed. Porto Alegre: Bookman. 